\title{
Change in the postoperative intervertebral space height and its impact on clinical and radiological outcomes after ACDF surgery using a zero-profile device: a single-Centre retrospective study of 138 cases
}

Haimiti Abudouaini ${ }^{1}$, Chengyi Huang ${ }^{1}$, Hao Liu ${ }^{1 *}$, Ying Hong ${ }^{2}$, Beiyu Wang ${ }^{1}$, Chen Ding ${ }^{1}$, Yang Meng ${ }^{1}$ and Tingkui $\mathrm{Wu}^{1}$

\begin{abstract}
Background: The effects of postoperative intervertebral height $(\mathrm{IH})$ changes on the clinical and radiological outcomes after anterior cervical decompression and fusion (ACDF) surgery using a zero-profile device remain unclear.

Methods: We retrospectively reviewed patients who had undergone ACDF using a zero-profile device from March 2012 to February 2016 at our institution. Based on the postoperative $\mathrm{H}$ variation, the patients were divided into group A with postoperative $\mathrm{IH} 0$ to $2 \mathrm{~mm}$, group B with postoperative $\mathrm{IH} 2$ to $4 \mathrm{~mm}$, and group $\mathrm{C}$ with postoperative $\mathrm{IH}$ greater than $4 \mathrm{~mm}$. Clinical efficacy was evaluated using JOA, VAS, and NDI scores in the groups. Imaging parameters including the $\mathrm{H}$, cervical lordosis, fusion rate, intervertebral foramen (IVF) diameter and complications such as subsidence, dysphagia, and ASD were also compared across the three groups.

Results: The average $\mathrm{IH}$ increased significantly from $6.72 \mathrm{~mm}$ preoperatively to $10.46 \mathrm{~mm} 1$ week after surgery, and then gradually decreased to $7.48 \mathrm{~mm}$ at the final follow-up. The fusion rate was $61.90 \%$ in group $\mathrm{A}, 63.23 \%$ in group B, 53.57\% in group C at 3 months, $73.81 \%$ in group A, 79.41\% in group B, 67.86\% in group C at 6 months, $90.48 \%$ in group $A, 95.59 \%$ in group $B, 92.86 \%$ in group $C 1$ year after surgery, and at the last follow-up, the fusion rate of three groups was all 100\%. The IVF diameter was $6.52 \pm 1.80 \mathrm{~mm}$ in group $A, 9.55 \pm 2.36 \mathrm{~mm}$ in group $B$, and $9.34 \pm 1.62 \mathrm{~mm}$ in group C. ASD at the superior and inferior levels affected 11.90 and $16.67 \%$ patients in group A, 5.88 and $7.38 \%$ in group B, and 14.28 and $10.71 \%$ in group C. Regarding the 3 groups, the subsidence rates were $7.14,4.41$, and $14.29 \%$, respectively.
\end{abstract}

*Correspondence: liuhaospine@163.com

'Department of Orthopedic Surgery, West China Hospital, Sichuan University, No. 37 Guo Xue Xiang Rd, Chengdu 610041, Sichuan, China

Full list of author information is available at the end of the article

C C The Author(s). 2021 Open Access This article is licensed under a Creative Commons Attribution 4.0 International License, which permits use, sharing, adaptation, distribution and reproduction in any medium or format, as long as you give appropriate credit to the original author(s) and the source, provide a link to the Creative Commons licence, and indicate if changes were made. The images or other third party material in this article are included in the article's Creative Commons licence, unless indicated otherwise in a credit line to the material. If material is not included in the article's Creative Commons licence and your intended use is not permitted by statutory regulation or exceeds the permitted use, you will need to obtain permission directly from the copyright holder. To view a copy of this licence, visit http://creativecommons.org/licenses/by/4.0/. The Creative Commons Public Domain Dedication waiver (http://creativecommons.org/publicdomain/zero/1.0/) applies to the data made available in this article, unless otherwise stated in a credit line to the data. 
Conclusions: No clear correlation was found between $\mathrm{IH}$ changes and clinical efficacy within a year of surgery. However, the $\mathrm{IH}$ may affect various complications after ACDF. If postoperative $\mathrm{IH}$ changes are maintained at 2 to 4 $\mathrm{mm}$ after a year, a satisfactory imaging parameters and relatively low complications may be achieved after ACDF surgery using a zero-profile device.

Keywords: Anterior cervical decompression and fusion, Intervertebral height, Zero-profile, Fusion rate, Adjacent segment degeneration

\section{Background}

Cervical disc degenerative disease (CDDD) is a spinal disorder that commonly affects middle-aged and older adults and may cause neck discomfort, radiating upper extremity pain, and neurologic abnormalities. Surgery is recommended if the patient does not respond to conservative treatment. Anterior cervical decompression and fusion (ACDF) using a traditional plate-cage construct (PCC) system is the main spinal surgery approach to treat symptomatic cervical disc disease [1]. However, postoperative axial pain and biomechanical instability leading to degeneration at the adjacent stage are likely caused by improper intervertebral distraction [2-5]. A zero-profile device is an alternative effective ACDF implant that can reduce adjacent segment degeneration to avoid implant contact with soft tissue in front of the cervical spine, likely preventing postoperative dysphagia [6-8].

Satisfactory reconstruction and consistent maintenance of the intervertebral height $(\mathrm{IH})$ influence the cervical surgery outcome. IH distraction is associated with neck pain, the occurrence of ASD and neural functional recovery after cervical surgery [5]. However, compared with studies examining surgical skills such as IH distraction and reconstruction techniques, few studies have assessed the connection with $\mathrm{IH}$ maintenance and clinical efficacy after ACDF using a Zero-p device.

Here, we examined IH changes following zero-profile ACDF and analysed the relationship between $\mathrm{IH}$ and clinical efficacy and imaging parameters.

\section{Methods}

Ethical approval for this study was granted by our institutional ethics committee. All the participants provided informed consent for analysis of their clinical data.

\section{Patient population}

The data on single-level CDDD were collected retrospectively from March 2012 to January 2016 at our institution. The primary inclusion criteria were patients aged 18-65 years, symptomatic cervical disc degenerative diseases (CDDDs) with spondylotic radiculopathy or myelopathy at 1 level from $\mathrm{C} 3$ to $\mathrm{C} 7$ that correlate with imaging findings, patients showing a poor effect on conservative treatment or unclear improvement after at least
3 months with a worsening condition. Patients were excluded if they had received cervical disc arthroplasty (CDA), were treated with hybrid surgery (CDA incorporated with fusion), had undergone ACDF using another implant, or had been treated with multilevel surgery. Patients with infections, osteoporosis, spinal fractures, spinal deformity, allergy to the device material, ankylosing spondylitis, rheumatoid arthritis, and previous cervical spine surgery were also excluded.

\section{Surgical technique}

All anterior fusions were performed using the SmithRobinson technique and a right-sided approach by the same surgeon. After confirmation and exposure of the appropriate vertebral levels, a Caspar distracter was used, and disc material was removed. The endplate cartilage was scraped using a curette or high-speed electric drill to prepare for bone grafting. The posterior longitudinal ligament, osteophytes, and other compressive elements were removed to ensure adequate dural and neural decompression. After measuring the intervertebral height and width, the appropriate Zero-P implant filled with b-tricalcium phosphate was inserted with an implant holder/aiming device.

\section{Postoperative management}

The patients wore a soft collar for 3 months after surgery, began functional exercise a day after the operation and were given a home exercise regimen at discharge.

\section{Clinical evaluation}

The clinical outcomes were evaluated using the visual analog scale (VAS) arm and neck score, Japanese Orthopedic Association (JOA) score, and neck disability index (NDI). The VAS evaluated neck and arm pain, the JOA score evaluated myelopathy status, and the NDI assessed neck function. These clinical outcomes were measured preoperatively and at 3 months, 6 months, and 12 months and at the last postoperative follow-up.

\section{Radiologic assessment}

Independent radiologists performed radiographic imaging using standing lateral, flexion and extension radiographs. Radiologic measurements included the $\mathrm{IH}$, cervical curvature, the functional spine unit (FSU), the 
intervertebral foramen (IVF) diameter, adjacent segment degeneration (ASD), the fusion rate and implant subsidence. The IH was calculated using the formula $\mathrm{a}-(\mathrm{b}+\mathrm{c})$, where $\mathrm{a}$ is the distance from the midpoint of the upper endplate of the cephalad vertebral body to the lower endplate of the caudal vertebral body, $\mathrm{b}$ is the distance from the midpoint of the upper endplate of the cephalad vertebral body to the midpoint of the lower endplate, and $\mathrm{c}$ is the distance from the midpoint of the upper endplate to the midpoint of the lower endplate (Fig. 1). Cervical sagittal alignment was measured at the $\mathrm{C} 2-7$ angle. Local kyphosis was measured using the endplate method [9]. The FSU angle refers to the angle between lines drawn at the superior margin of the superior vertebral body and inferior margin of the inferior body. ASD is defined as the presence of 1) new or enlarged ossification of the anterior longitudinal ligament, 2) new or increased narrowing of the disc space by $>30 \%, 3$ ) new or obvious enlarging osteophyte formation and 4) endplate sclerosis [10]. Radiological fusion refers to the presence of $\leq 2^{\circ}$ motion and/or $\leq 2 \mathrm{~mm}$ of motion of the interspinous distance on flexion-extension X-rays [11]. Implant subsidence refers to a loss in the FSU height $>2 \mathrm{~mm}$.

\section{Statistics}

Radiographic assessments were performed twice by two independent surgeons, and the mean values were used for statistical analysis. The results are presented as means \pm standard deviation. Student's t-test or the Mann-Whitney U test was used to compare continuous data between two groups, depending on whether the data were normally distributed. Chi-squared test or Fisher's exact test was used to compare categorical data between the groups. Odds ratios with 95\% confidence intervals were calculated for differences between the groups. $\mathrm{P}=<0.05$ was considered statistically significant. SPSS version 22.0 (IBM Corp.) was used for statistical analyses.

\section{Results}

One hundred forty-eight patients were enrolled in the study; among them, ten patients were excluded because of incomplete postoperative imaging data and did not attend the final follow-up. Thus, 138 consecutive patients (63 female and 75 male) qualified for further analyses. The mean age was $48.03 \pm 9.51$ years, with a mean follow-up of $22.83 \pm 6.272$ months (range: 18-36 months). Twelve patients were at the C3-4 level, 34 at the C4-5 level, 71 at C5-6, and 21 at C6-7.

\section{Intervertebral height}

The average $\mathrm{IH}$ increased significantly from $6.72 \mathrm{~mm}$ preoperatively to $10.46 \mathrm{~mm}$ at 1 week after surgery. After that, the average $\mathrm{IH}$ progressively decreased to $9.58 \mathrm{~mm}$ at 3 months, $8.73 \mathrm{~mm}$ at 6 months, and $7.58 \mathrm{~mm}$ at 1 year $(p=<0.05)$. The average $\mathrm{IH}$ was $7.48 \mathrm{~mm}$ at the final follow-up ( $p=>0.05$ ) (Table 1, Fig. 2). To investigate the great importance of maintaining the $\mathrm{IH}$ after ACDF using a zero-profile device, the patients were grouped by postoperative $\mathrm{IH}$ change into three groups; the variation value of $\mathrm{IH}$ was $0-2 \mathrm{~mm}$ in group $\mathrm{A}, 2-4$ $\mathrm{mm}$ in group $\mathrm{B}$, and greater than $4 \mathrm{~mm}$ in group C. Group A comprised 42 patients ( 25 male and 17 female; average age $=45.06 \pm 6.31$ years), group B comprised 68 patients (40 male and 28 female; average age $=43.21 \pm$ 7.53 years), and group $C$ comprised 28 patients (16 male and 12 female; average age $=46.51 \pm 7.6$ years). The demographic factors, size of the zero-profile device and preoperative ASD were not significantly different among the 3 groups (Table 2).

\section{Clinical outcomes}

The clinical symptoms markedly improved after the operation in all the patients, and the mean JOA score was elevated in all the groups (Table 3). The mean VAS and NDI scores decreased significantly. No significant
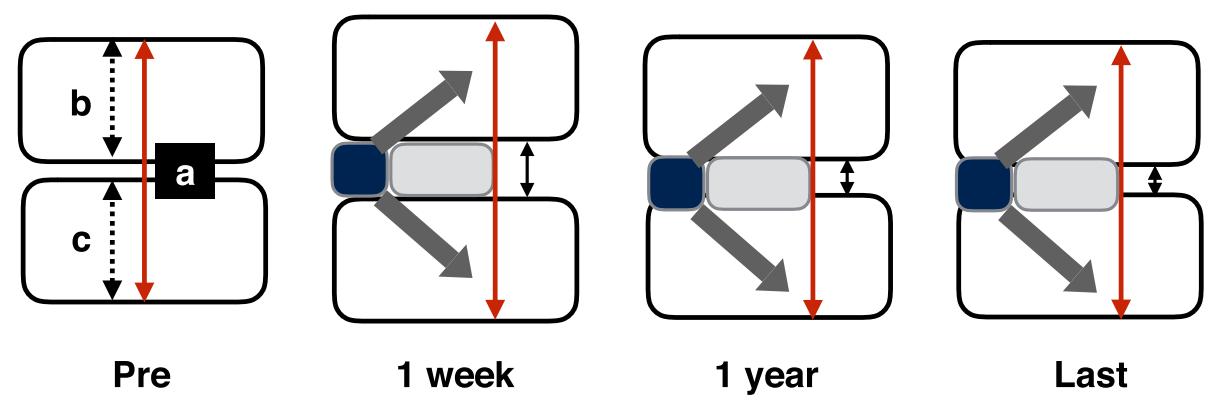

Fig. 1 Representation of the radiographic measurement of the intervertebral height $(\mathrm{IH})$ and its postoperative trend. The IH (black solid arrow between two vertebrae $)=a-(b+c)$, where a (red arrow) is the distance from the midpoint of the upper endplate of the upper vertebral body and that of the lower endplate of the lower vertebral body, $b$ is the distance from the midpoint of the upper endplate of the upper vertebral body to the midpoint of the lower endplate, and $\mathrm{c}$ is the distance from the midpoint of the upper endplate to the midpoint of the

lower endplate 
Table 1 Intervertebral space height of the patients

\begin{tabular}{lllllll}
\hline & Preoperative & $\mathbf{1}$ week & $\mathbf{3}$ month & $\mathbf{6}$ month & 1 year & Last follow-up \\
\hline C3/4 & 7.54 & 11.14 & 10.72 & 9.61 & 8.25 & 8.11 \\
C4/5 & 6.87 & 10.15 & 9.97 & 8.75 & 7.36 & 7.23 \\
C5/6 & 5.26 & 10.73 & 9.28 & 9.96 & 6.17 & 6.14 \\
C6/7 & 6.11 & 10.97 & 9.16 & 8.72 & 7.64 & 7.58 \\
Overall & 6.72 & 10.46 & 9.58 & 8.73 & 7.58 & 7.48 \\
\hline
\end{tabular}

differences were found in the clinical parameters among the three groups.

\section{Radiological outcomes}

The preoperative radiological parameters, postoperative FSU and cervical alignment were not significantly different among the three groups (all, $p=>0.05$ ). The fusion rate was $61.90 \%$ in group A, $63.23 \%$ in group B, $53.57 \%$ in group $\mathrm{C}$ at 3 months, $73.81 \%$ in group $\mathrm{A}, 79.41 \%$ in group $\mathrm{B}, 67.86 \%$ in group $\mathrm{C}$ at 6 months, $90.48 \%$ in group A, $95.59 \%$ in group B, $92.86 \%$ in group C 1 year after surgery, and at the last follow-up, the fusion rate of three groups was all $100 \%$. The fusion rate of patients in group $\mathrm{C}$ was significantly lower than that in the other two groups in the first 6 months $(p=<0.05)$. The mean IVF diameter was $6.52 \pm 1.80 \mathrm{~mm}$ (variation $=2.58 \pm 0.51$ $\mathrm{mm}$ ) in group A, $9.55 \pm 2.36 \mathrm{~mm}$ (variation $=0.87 \pm 1.21$ $\mathrm{mm}$ ) in group $\mathrm{B}$, and $9.34 \pm 1.62 \mathrm{~mm}$ (variation $=1.47 \pm$ $1.30 \mathrm{~mm}$ ) in group C. The IVF diameter in group A was significantly different than that in the other two groups, while the variation differed significantly between groups A and B 1 year post-surgery (Table 4).

Based on radiography, the ASD at the superior level affected $11.90 \%(5 / 42)$ of group A patients, 5.88\% (4/68) of group B patients, and $14.28 \%$ (4/28) of group C patients. The ASD at the inferior level affected 16.67\% (7/
42) of group A patients, $7.35 \%$ (5/68) of group B patients, and $10.71 \%(3 / 28)$ of group C patients. Group B rates were significantly lower than those of the other groups $(p=<0.05)$. The incidence of implant subsidence was $7.14 \%$ in group A, $4.41 \%$ in group B, and $14.29 \%$ in group $C$. The rates in group B were significantly different from those in group $\mathrm{C}$ for implant subsidence. The incidence rates of dysphagia and local kyphosis did not differ significantly among the groups (Table 5).

\section{Discussion}

Effective IH improvement is crucial for good outcomes after cervical spine surgery. Undesirable postoperative $\mathrm{IH}$ has been linked to a higher incidence of postsurgery axial symptoms and ASD [12]. Thus, effective intraoperative restoration and postoperative maintenance of $\mathrm{IHs}$ are necessary. However, compared with surgical skills such as IH distraction and reconstruction techniques, few studies have assessed the association between IH maintenance and the clinical efficacy after ACDF using a Zero-p device.

The intervertebral height $(\mathrm{IH})$ was effectively improved in all patients. The average $\mathrm{IH}$ rose significantly from $6.72 \mathrm{~mm}$ preoperatively to $10.46 \mathrm{~mm} 1$ week before being progressively reduced to $9.58 \mathrm{~mm}$ at 3 months, 8.73 $\mathrm{mm}$ at 6 months, $7.58 \mathrm{~mm}$ at 1 year, and $7.50 \mathrm{~mm}$ at the

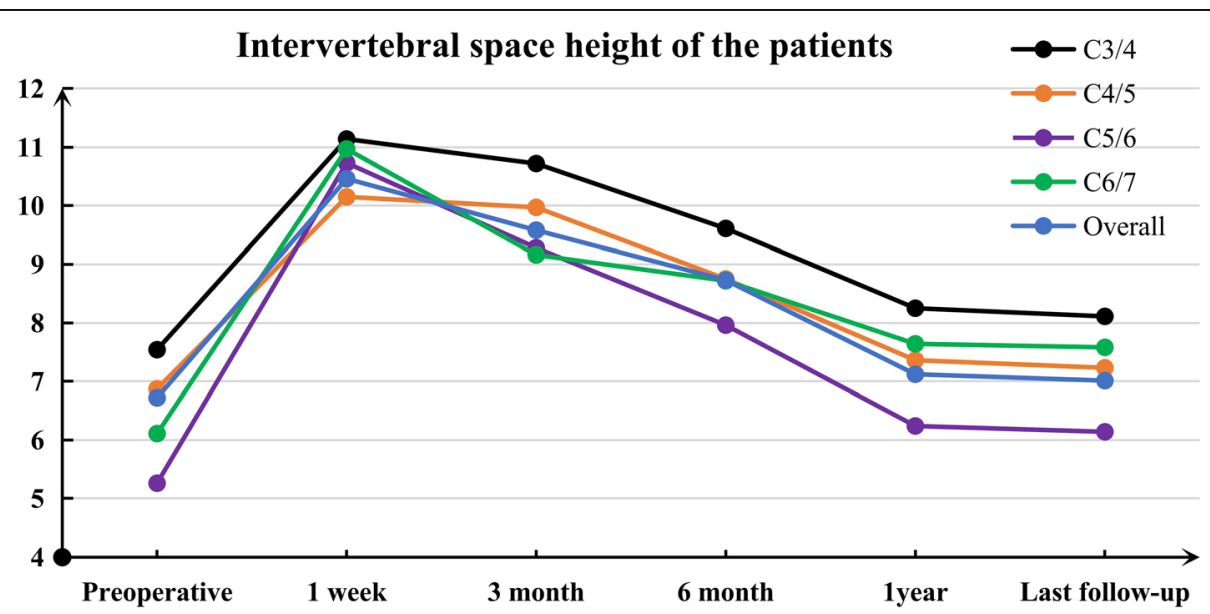

Fig. 2 Trend chart of the intervertebral height $(\mathrm{IH})$ after ACDF using the Zero-P device. The $\mathrm{IH}$ increased significantly 1 week after surgery, and then it was progressively reduced within the first year. However, a balance was achieved and no obvious reduction was observed in the $\mathbb{I H} 1$ year after surgery 
Table 2 Demographic and baseline data

\begin{tabular}{|c|c|c|c|c|}
\hline Group & $\begin{array}{l}\text { Group A } \\
\text { (ISH change }<2 \mathrm{~mm} \text { ) }\end{array}$ & $\begin{array}{l}\text { Group B } \\
\text { (ISH change 2-4 mm) }\end{array}$ & $\begin{array}{l}\text { Group C } \\
\text { (ISH change }>4 \mathrm{~mm} \text { ) }\end{array}$ & $\mathbf{P}$ \\
\hline No. & 42 & 68 & 28 & \\
\hline Age (y) & $45.06 \pm 6.31$ & $43.21 \pm 7.53$ & $46.51 \pm 7.61$ & 0.061 \\
\hline Male & 25 & 40 & 16 & 0.264 \\
\hline Female & 17 & 28 & 12 & 0.162 \\
\hline \multicolumn{5}{|l|}{ Level (\%) } \\
\hline $3 / 4$ & 9.52 & 7.35 & 10.71 & 0.281 \\
\hline $4 / 5$ & 23.81 & 26.47 & 21.43 & 0.310 \\
\hline $5 / 6$ & 52.38 & 50.00 & 53.57 & 0.346 \\
\hline $6 / 7$ & 14.29 & 16.18 & 14.26 & 0.331 \\
\hline \multicolumn{5}{|c|}{ Implant height } \\
\hline $5 \mathrm{~mm}$ & $7.14 \%(3 / 42)$ & $8.82 \%(6 / 68)$ & $10.71 \%(3 / 28)$ & 0.873 \\
\hline $6 \mathrm{~mm}$ & $57.14 \%(24 / 42)$ & $54.41 \%(37 / 68)$ & $57.14 \%(17 / 28)$ & 0.848 \\
\hline $7 \mathrm{~mm}$ & $30.95 \%(13 / 42)$ & $30.88 \%(21 / 68)$ & $28.57 \%(7 / 28)$ & 0.830 \\
\hline $8 \mathrm{~mm}$ & $4.76 \%(2 / 42)$ & $5.88 \%(4 / 68)$ & $3.57 \%(1 / 28)$ & 0.890 \\
\hline \multicolumn{5}{|c|}{ Preoperative ASD } \\
\hline Superior & $9.52 \%(4 / 42)$ & $7.35 \%(5 / 68)$ & $7.14 \%(2 / 28)$ & 0.905 \\
\hline Inferior & $14.28 \%(6 / 42)$ & $11.76 \%$ (8/68) & $10.71 \%$ (3/28) & 0.888 \\
\hline
\end{tabular}

ISH Intervertebral space height, ASD Adjacent segment degeneration

last follow-up. Thus, the IH changed subtly 1 year after ACDF (Fig. 2). Our data revealed no clear association between the postoperative disc height change and any clinical outcomes in the 1st year after ACDF surgery.

A study involving 37 1-level procedures, 50 2-level procedures and 13 -level procedures evaluated the effects of the $\mathrm{IH}$ on overall outcomes after ACDF and found that the $\mathrm{IH}$ changed from a preoperative mean of $5.49 \pm 1.17 \mathrm{~mm}$ to $6.62 \pm 1.12 \mathrm{~mm}$ at 12 months postsurgery (mean change $=1.13 \pm 1.33 \mathrm{~mm}$ ) [13] (Fig. 3). Here, to avoid biomechanical changes due to adjacent surgical segments that may affect postoperative $\mathrm{IH}$, we only included 1-level ACDF surgery with zero-profile implants.

Achieving complete nerve root decompression in cervical spondylotic radiculopathy patients with intervertebral foramen stenosis is challenging. Frequently, no remission for radicular pain or reoccurrence is observed after temporary relief in such patients. Although the pathogenesis of cervical radiculopathy is not completely understood, stenosis of the intervertebral foramina is considered among its main mechanistic underpinnings [14]. Additionally, narrowing of the intervertebral foramen after surgery is a risk factor for postoperative recurrence of neurological symptoms [15]. Therefore, the intervertebral foramen, as the doorway of the nerve root, plays an important role in radiculopathy and surgical treatment of intervertebral foramen diseases. Here, although the IVF diameter in group A patients was significantly smaller than that in groups B and C 1 year after surgery, this condition was not reflected

Table 3 JOA, VAS and NDI scores for three groups

\begin{tabular}{|c|c|c|c|c|}
\hline & ISH change $<2 \mathrm{~mm}$ & ISH change $2-4 \mathrm{~mm}$ & ISH change $>4 \mathrm{~mm}$ & $\mathbf{P}$ \\
\hline \multicolumn{5}{|l|}{ JOA scores } \\
\hline one week & $11.73 \pm 1.86$ & $12.92 \pm 2.46$ & $12.84 \pm 2.59$ & 0.739 \\
\hline 12-month & $13.35 \pm 2.23$ & $13.66 \pm 1.47$ & $13.30 \pm 1.62$ & 0.642 \\
\hline \multicolumn{5}{|l|}{ VAS scores } \\
\hline 1 week & $1.95 \pm 0.58$ & $1.91 \pm 0.22$ & $1.86 \pm 0.64$ & 0.530 \\
\hline 1 year & $1.82 \pm 0.62$ & $1.75 \pm 0.84$ & $1.69 \pm 0.27$ & 0.963 \\
\hline \multicolumn{5}{|l|}{ NDI scores } \\
\hline one week & $21.74 \pm 0.68$ & $21.67 \pm 3.59$ & $21.46 \pm 2.94$ & 0.744 \\
\hline 12-month & $19.53 \pm 0.82$ & $18.95 \pm 4.67^{\mathrm{a}, \mathrm{b}}$ & $17.19 \pm 4.22$ & 0.528 \\
\hline
\end{tabular}


Table 4 Radiographic assessments of patients in three groups

\begin{tabular}{|c|c|c|c|}
\hline Group & ISH change $<2 \mathrm{~mm}$ & ISH change $2-4 \mathrm{~mm}$ & ISH change $>4 \mathrm{~mm}$ \\
\hline \multicolumn{4}{|c|}{ C2-7 Cobb angle $\left(^{\circ}\right)$} \\
\hline 1 week & $14.52 \pm 3.6$ & $12.47 \pm 2.9$ & $13.65 \pm 3.2$ \\
\hline 1 year & $12.26 \pm 9.36$ & $11.91 \pm 3.1$ & $11.34 \pm 4.5$ \\
\hline Variation value & $1.40 \pm 4.80$ & $1.15 \pm 2.4$ & $1.33 \pm 2.07$ \\
\hline \multicolumn{4}{|c|}{ Cobb angle of fused segments $\left(^{\circ}\right)$} \\
\hline 1 week & $16.4 \pm 2.5$ & $14.3 \pm 2.9$ & $16.1 \pm 2.2$ \\
\hline 1 year & $12.8 \pm 1.7$ & $12.4 \pm 1.5$ & $13.5 \pm 1.0$ \\
\hline Variation value & $1.8 \pm 3.2$ & $2.1 \pm 1.8$ & $3.0 \pm 2.9$ \\
\hline \multicolumn{4}{|c|}{ Diameter of IVF (mm) } \\
\hline 1 week & $9.14 \pm 2.38$ & $10.54 \pm 1.89$ & $10.83 \pm 1.50$ \\
\hline 1 year & $6.52 \pm 1.80$ & $9.55 \pm 2.36^{\mathrm{a}}$ & $9.34 \pm 1.62^{a}$ \\
\hline Variation value & $2.58 \pm 0.51$ & $0.87 \pm 1.21^{\mathrm{a}}$ & $1.47 \pm 1.30$ \\
\hline \multicolumn{4}{|l|}{ Fusion rate (\%) } \\
\hline 3 months & $61.90 \%(29 / 42)^{c}$ & $63.23 \%(43 / 68)^{c}$ & $53.57 \%(15 / 28)$ \\
\hline 6 months & $73.81 \%(31 / 42)^{c}$ & $79.41 \%(54 / 68)^{c}$ & $67.86 \%(19 / 28)$ \\
\hline 1 year & $90.48 \%(38 / 42)$ & $95.59 \%(65 / 68)^{c}$ & $92.86 \%(26 / 28)$ \\
\hline Final follow-up & $100 \%$ & $100 \%$ & $100 \%$ \\
\hline
\end{tabular}

ISH Intervertebral space height, IVF Intervertebral foramen; Diameter of IVF = (longitudinal diameter of IVF + transverse diameter of IVF) / 2

in the patients' radicular symptoms. Our study sought to verify the connection between $\mathrm{IH}$ variation and overall outcomes, reflecting the 1-year follow-up after surgery.

An in vitro biomechanical study used a calibrated distractor and a subminiature load cell on 17 cadaveric cervical specimens to investigate the effects of $\mathrm{IH}$ and distractive forces on a cervical spine model. In that study, the longer was the intervertebral space distance, the greater was the compressive load produced between the implant and vertebral body end plate, which may decrease the fusion rate [16]. Here, the fusion rate in group $\mathrm{C}$ patients was significantly lower than that in groups $\mathrm{A}$ and $B$ in the first 6 months, possibly because the height of the intervertebral space declined too much in a short time. This effect may concentrate the compressive load in the endplate with the narrowest intervertebral space, negatively affecting bone fusion. This possibility should be tested by analysing the influence of stress distribution on bone fusion using ACDF models with different intervertebral heights through finite elements or biomechanical tests.

Prosthesis subsidence affects 7-25\% of patients undergoing ACDF surgery using the Zero-P device [17-19]. Our data revealed $14.29 \%$ subsidence in group $C$ patients, a level that was significantly higher than that in the other 2 groups. Because previous studies have identified various causes and risk factors for implant subsidence after ACDF $[19,20]$, it is unlikely that implant subsidence was caused by a single factor. However, our data clearly show that the lower fusion rate caused by an IH change $>4 \mathrm{~mm}$ is a non-negligible factor for the higher subsidence rate after ACDF.

We found that $\mathrm{IH}$ is strongly associated with the occurrence of ASD, consistent with a prior study [4]. In

Table 5 Comparison of complications among three groups

\begin{tabular}{llll}
\hline Group & ISH change $<\mathbf{2 ~} \mathbf{~ m m}$ & ISH change $\mathbf{2 - 4} \mathbf{~ m m}$ & ISH change $>\mathbf{4} \mathbf{~ m m}$ \\
\hline Adjacent-level degeneration & & & \\
$\quad$ Superior & $28.57 \%(12)$ & $13.24 \%(9)^{\mathrm{a}}$, & $21.43 \%(6)$ \\
Inferior & $30.95 \%(13)$ & $16.18 \%(11)^{\mathrm{a}, \mathrm{c}}$ & $28.57 \%(8)$ \\
Axial symptoms & $26.19 \%(11)$ & $11.76 \%(8)^{\mathrm{a}}$ & $17.85 \%(5)$ \\
Dysphagia & $5.4 \%(2)$ & $4.41 \%(3)$ & $5.26 \%(1)$ \\
Local kyphosis & $9.52 \%(4)$ & $13.24 \%(9)$ & $14.29 \%(4)$ \\
Implant subsidence & $7.14 \%(3)$ & $4.41 \%(3)^{\mathrm{b}}$ & $14.29 \%(4)$ \\
Facet joint degeneration [11] & 3 points & 2 points & 2 points \\
\hline
\end{tabular}



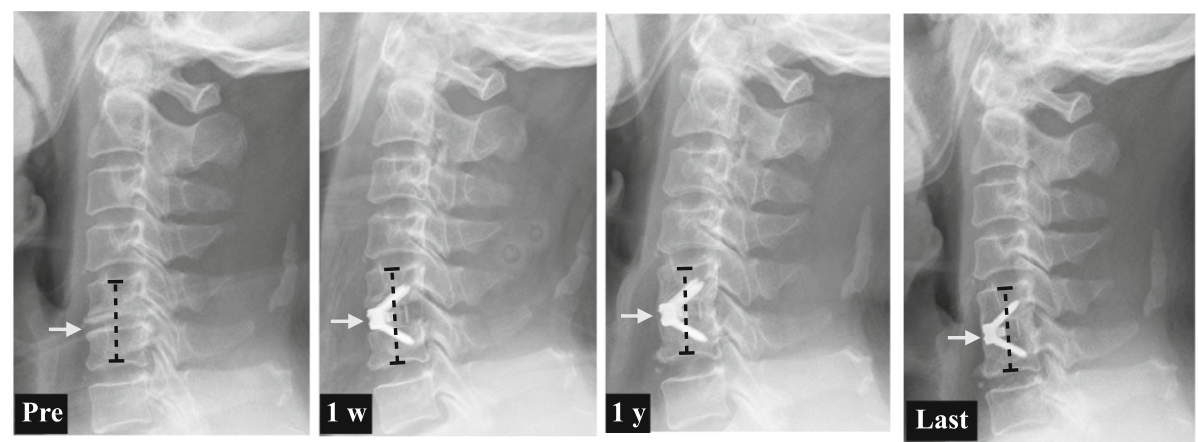

Fig. 3 Case report: A middle-aged patient who had undergone C5/6 ACDF using the Zero-P device. The mean IH was increased significantly from $6.52 \mathrm{~mm}$ preoperatively to $10.37 \mathrm{~mm}$ at 1 week, and then it decreased to $7.84 \mathrm{~mm}$ at 1 year and $7.39 \mathrm{~mm}$ at the last follow-up (white arrows)

that study, the average $\mathrm{IH}$ variation was $1.8 \mathrm{~mm}$ in the ASD group vs $2 \mathrm{~mm}$ in the non-ASD group over a twoyear follow-up. Li et al. [21] reported that excessive disc space distraction is a considerable risk factor for the development of radiographic ASD after patients had undergone ACDF polyetheretherketone (PEEK) cages with an anterior plate. The main reason may be that distraction of the fusion level by cage insertion exerts significant mechanical stress on the adjacent levels. Although prostheses with different design concepts were used, the same results were obtained in our study; ASD was significantly lower in group B than in groups A and C. Appropriate IH provides a better surgical view during decompression and prosthesis insertion, which is a prerequisite to improve the effectiveness and safety of using the Zero-p implant system. Small IHs might result in inadequate decompression or the formation of pseudarthrosis; conversely, large IHs may elevate mechanical stress on adjacent levels [16].

Our study has the following limitations. Because it was a retrospective study, patient selection bias was unavoidable. Thus, randomized controlled studies are needed to validate our findings. Although our measuring method was conducted according to previous studies, we acknowledge that potentially inherent radiographic imaging error may be a major limitation. Additionally, we did not evaluate effective methods for maintaining the postoperative IH. Given that our study mainly investigated the effects of postoperative IH changes on clinical and radiographic outcomes, further studies must focus on effective interventions for maintaining the postoperative $\mathrm{IH}$ at 2 to $4 \mathrm{~mm}$.

\section{Conclusion}

We found that ACDF surgery using a zero-profile device could not sustain the IH attained 1 week after surgery. No clear correlation was found between IH changes and clinical efficacy within a year of surgery. However, the
IH may affect various complications within a year after ACDF. If postoperative $\mathrm{IH}$ changes can be maintained at 2 to $4 \mathrm{~mm}$ after a year, a satisfactory fusion rate and IVF diameter and a relatively low implant subsidence and ASD may be achieved after ACDF surgery using a zeroprofile device.

\section{Abbreviations}

IH: Intervertebral height; ACDF: Anterior cervical decompression and fusion;

JOA: Japanese Orthopedics Association; NDI: Neck Disability Index;

VAS: Visual analogue scale; IVF: Intervertebral foramen; ASD: Adjacent segment degeneration; CDDD: Cervical disc degenerative disease; PCC: Platecage construct; CDA: Cervical disc arthroplasty; FSU: Functional spine unit

\section{Acknowledgements}

Not applicable.

\section{Authors' contributions}

HA, BYW and HL contributed to the design of the study; BYW, YM, YH collected radiographs and related data; YH and CD contributed significantly to the analysis and manuscript preparation; HA and TKW performed the data analyses and wrote the manuscript; $\mathrm{CYH}$ and $\mathrm{YH}$ helped perform the analysis with constructive discussions; All authors have read and approved the manuscript

\section{Funding}

The authors would like to acknowledge the Department of Science and Technology of Sichuan Province (Grant number: 2019YFQ0002) awarded to Hao Liu for funding design this study, Sichuan Province Science, Technology Support Program (Grant number: 2020YFS0084) awarded to Beiyu Wang for funding the cost of collecting the data, Department of Science and Technology of Sichuan Province (Grant number: 2018SZ0045) awarded to Ying Hong for funding the expenses during the writing.

\section{Availability of data and materials}

The datasets used and/or analysed during the current study are available from the corresponding author on reasonable request.

\section{Declarations}

Ethics approval and consent to participate

The study was conducted after ethical approval was obtained from the West China Hospital of Sichuan University College Ethical Committee, and all the participants provided written informed consent.

Ethical approval was granted by the West China Hospital of Sichuan

University Human Research Ethics Committee, Health and Medical Research Human Research Ethics Committee, and all the participants provided written informed consent before the start of the study. 


\section{Consent for publication}

Not applicable.

\section{Competing interests}

No conflict of interest exists in the submission of this manuscript

\section{Author details}

'Department of Orthopedic Surgery, West China Hospital, Sichuan University, No. 37 Guo Xue Xiang Rd, Chengdu 610041, Sichuan, China. ${ }^{2}$ Department of Anesthesia and Operation Center / West China School of Nursing, West China Hospital, Sichuan University, No. 37 Guo Xue Xiang, Chengdu 610041, Sichuan, China.

Received: 3 November 2020 Accepted: 6 June 2021

Published online: 14 June 2021

\section{References}

1. Chagas $H$, Domingues F, et al. Cervical spondylotic myelopathy: 10 years of prospective outcome analysis of anterior decompression and fusion. Surg Neurol. 2005;64(Suppl 1):30-5 discussion S1:35-6.

2. Godlewski B, Stachura MK, Czepko RA, Banach M, Czepko R. Analysis of changes in cervical spinal curvature and intervertebral disk space height following ACDF surgery in a group of 100 patients followed up for 12 months. J Clin Neurosci. 2018;52:92-9. https://doi.org/10.1016/j.jocn.2018.04. 005.

3. Kawakami M, Tamaki T, Yoshida M, Hayashi N, Ando M, Yamada H. Axial symptoms and cervical alignments after cervical anterior spinal fusion for patients with cervical myelopathy. J Spinal Disord. 1999;12(1):50-6.

4. Li H, Lou J, Liu H, Wang B. Effect of intervertebral disc height on the range of motion and clinical outcomes after single-level implantation of prestige LP cervical disc prosthesis. Clin Neurol Neurosurg. 2016;148:1-4. https://doi. org/10.1016/j.clineuro.2016.06.010.

5. Bai J, Zhang X, Zhang D, Ding W, Shen Y, Zhang W, et al. Impact of over distraction on occurrence of axial symptom after anterior cervical discectomy and fusion. Int J Clin Exp Med. 2015;8(10):19746-56.

6. Barbagallo GM, Romano D, et al. Zero-P: a new zero-profile cage-plate device for single and multilevel ACDF. A single institution series with four years maximum follow-up and review of the literature on zero-profile devices. Eur Spine J. 2013;22(Suppl 6):S868-78.

7. Li Z, Zhao Y, Tang J, Ren D, Guo J, Wang H, et al. A comparison of a new zero-profile, stand-alone Fidji cervical cage and anterior cervical plate for single and multilevel ACDF: a minimum 2-year follow-up study. Eur Spine J. 2017;26(4):1129-39. https://doi.org/10.1007/s00586-016-4739-2.

8. Hofstetter CP, Kesavabhotla K, Boockvar JA. Zero-profile anchored spacer reduces rate of dysphagia compared with ACDF with anterior plating. J Spinal Disord Tech. 2015;28(5):E284-90. https://doi.org/10.1097/BSD.0b013 e31828873ed.

9. Bono CM, Schoenfeld A, Rampersaud R, Levi A, Grauer J, Arnold P, et al. Reproducibility of radiographic measurements for subaxial cervical spine trauma. Spine (Phila Pa 1976). 2011;36(17):1374-9. https://doi.org/10.1097/ BRS.0b013e318221e169.

10. Robertson JT, Papadopoulos SM, Traynelis VC. Assessment of adjacentsegment disease in patients treated with cervical fusion or arthroplasty: a prospective 2-year study. J Neurosurg Spine. 2005;3(6):417-23. https://doi. org/10.3171/spi.2005.3.6.0417

11. Hwang SL, Hwang YF, Lieu AS, et al. Outcome analyses of interbody titanium cage fusion used in the anterior discectomy for cervical degenerative disc disease. J Spinal Disord Tech. 2005;18(4):326-31. https:// doi.org/10.1097/01.bsd.0000164198.30725.2d

12. Matsunaga S, Kabayama S, Yamamoto T, Yone K, Sakou T, Nakanishi K. Strain on intervertebral discs after anterior cervical decompression and fusion. Spine (Phila Pa 1976). 1999;24(7):670-5. https://doi.org/10.1097/00007632-1 99904010-00011.

13. Basques B, Khan JM, Nolte MT, Louie P, Sayari A, Iloanya MN, et al. Do large increases in disc space height have consequences after ACDF? Spine J. 2019;19(9):S128. https://doi.org/10.1016/j.spinee.2019.05.277.

14. Ebraheim NA, An HS, Xu R, Ahmad M, Yeasting RA. The quantitative anatomy of the cervical nerve root groove and the intervertebral foramen. Spine (Phila Pa 1976). 1996;21(14):1619-23. https://doi.org/10.1097/ 00007632-199607150-00001.
15. Doo TH, Shin DA, Kim HI, Shin DG, Kim HJ, Chung JH, et al. Clinical relevance of pain patterns in osteoporotic vertebral compression fractures. J Korean Med Sci. 2008;23(6):1005-10. https://doi.org/10.3346/jkms.2008.23.6.1 005.

16. Truumees E, Demetropoulos CK, Yang KH, Herkowitz HN. Effects of disC height and distractive forces on graft compression in an anterior cervical corpectomy model. Spine (Phila Pa 1976). 2008;33(13):1438-41. https://doi. org/10.1097/BRS.0b013e318175c315.

17. Zhang Y, Liu H, Yang H, Pi B. Relationship between sagittal balance and axial symptoms in patients with cervical Spondylotic myelopathy treated with anterior cervical discectomy and fusion. J Investig Surg. 2020;33(5):40411. https://doi.org/10.1080/08941939.2018.1524948.

18. Ponnappan RK, Nassr A, et al. Anterior decompression, instrumentation, fusion techniques : discectomy, foraminotomy, disc space carpentry, The Textbook of Spinal Surgery. 3rd ed; 2011. p. 258-60.

19. Shen Y, Du W, et al. Comparison of zero-profile device versus plate-andcage implant in the treatment of symptomatic adjacent segment disease after anterior cervical discectomy and fusion: a minimum 2-year follow-up study. World Neurosurg. 2018;115:e226-32. https://doi.org/10.1016/j.wneu.2 018.04.019.

20. Noh SH, Zhang HY. Comparison among perfect- ${ }^{\oplus}$, zero-P ${ }^{\oplus}$, and plates with a cage in single-level cervical degenerative disc disease. BMC Musculoskelet Disord. 2018;19(1):33. https://doi.org/10.1186/s12891-018-1950-9.

21. Li J, Li Y, Kong F, Zhang D, Zhang Y, Shen Y. Adjacent segment degeneration after single-level anterior cervical decompression and fusion: disc space distraction and its impact on clinical outcomes. J Clin Neurosci. 2015;22(3):566-9. https://doi.org/10.1016/j.jocn.2014.08.019.

\section{Publisher's Note}

Springer Nature remains neutral with regard to jurisdictional claims in published maps and institutional affiliations.
Ready to submit your research? Choose BMC and benefit from:

- fast, convenient online submission

- thorough peer review by experienced researchers in your field

- rapid publication on acceptance

- support for research data, including large and complex data types

- gold Open Access which fosters wider collaboration and increased citations

- maximum visibility for your research: over $100 \mathrm{M}$ website views per year

At BMC, research is always in progress.

Learn more biomedcentral.com/submissions 